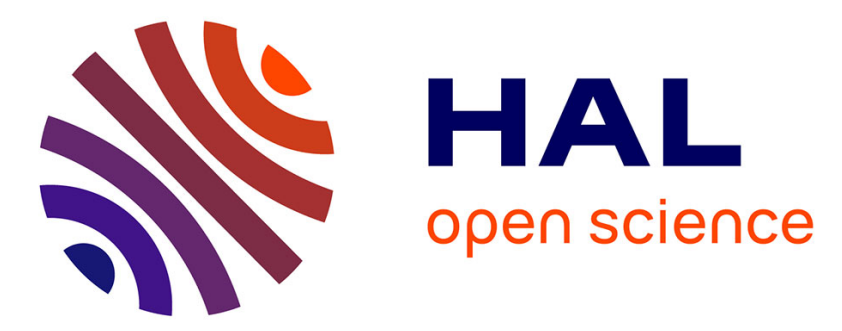

\title{
The emotions aroused by a vocational transition in adolescents: why, when and how are they socially shared with significant others?
}

Emmanuelle Vignoli, Frédéric Nils, Michael Parmentier, Pascal Mallet, Bernard Rimé

\section{To cite this version:}

Emmanuelle Vignoli, Frédéric Nils, Michael Parmentier, Pascal Mallet, Bernard Rimé. The emotions aroused by a vocational transition in adolescents: why, when and how are they socially shared with significant others?. International Journal for Educational and Vocational Guidance, 2019, 20 (3), pp.567-589. 10.1007/s10775-019-09417-z . hal-03509852

\section{HAL Id: hal-03509852 \\ https://hal.parisnanterre.fr/hal-03509852}

Submitted on 6 Jan 2022

HAL is a multi-disciplinary open access archive for the deposit and dissemination of scientific research documents, whether they are published or not. The documents may come from teaching and research institutions in France or abroad, or from public or private research centers.
L'archive ouverte pluridisciplinaire HAL, est destinée au dépôt et à la diffusion de documents scientifiques de niveau recherche, publiés ou non, émanant des établissements d'enseignement et de recherche français ou étrangers, des laboratoires publics ou privés. 


\title{
"The emotions aroused by a vocational transition in adolescents: Why, when, and how are they socially shared with significant others?"
}

\author{
Vignoli, Emmanuelle ; Nils, Frédéric ; Parmentier, Michaël ; Mallet, Pascal ; Rimé, Bernard
}

ABSTRACT

359 adolescents completed a self-report questionnaire that measured the emotional impact of an anticipated transition, social sharing modes, its psychological benefits, and relationships intimacy with mother, father and best friend. Results show that the transition has been shared rapidly, repeatedly, with several partners, especially intimates (mother, father, best friend). However, partners and motives of vocational sharing depend on the valence of the transition. The intensity of negative emotions is positively related to both the frequency and the depth of vocational sharing while the intensity of positive emotions is only related to the depth of the sharing. Perceived intimacy with significant others is positively associated with both the depth and the frequency of sharing, although to a lesser extent for the latter. In addition, the intrapersonal and interpersonal benefits are related to the depth of vocational sharing, but not to its frequency. The results are discussed in reference to knowledge and theories regarding the quality of relationships with significant others, emotions, social sharing of emotions in coping with vocational transitions and in career development. In particular, they show the importance of dissociating the frequency and depth of sharing in providing psychological benefits of social sharing and the importance to distinguish negative and positive emotions in this sharing process.

Vignoli, Emmanuelle ; Nils, Frédéric ; Parmentier, Michaël ; Mallet, Pascal ; Rimé, Bernard. The emotions aroused by a vocational transition in adolescents: Why, when, and how are they socially shared with significant others?. In: International Journal for Educational and Vocational Guidance, (2019) http:/l hdl.handle.net/2078.1/222875 -- DOI : 10.1007/s10775-019-09417-z

Le dépôt institutionnel DIAL est destiné au dépôt et à la diffusion de documents scientifiques émanant des membres de l'UCLouvain. Toute utilisation de ce document à des fins lucratives ou commerciales est strictement interdite. L'utilisateur s'engage à respecter les droits d'auteur liés à ce document, principalement le droit à l'intégrité de l'œuvre et le droit à la paternité. La politique complète de copyright est disponible sur la page Copyright policy
DIAL is an institutional repository for the deposit and dissemination of scientific documents from UCLouvain members. Usage of this document for profit or commercial purposes is stricly prohibited. User agrees to respect copyright about this document, mainly text integrity and source mention. Full content of copyright policy is available at Copyright policy 
The emotions aroused by a vocational transition in adolescents: Why, when and how are they socially shared with significant others?

Authors:

Emmanuelle Vignoli ${ }^{1}$, Conservatoire National des Arts et Métiers (CNAM), Center for Research on Work and Development, EA4132, HESAM, France

Frédéric Nils, UCLouvain, Louvain-la-Neuve, Belgium

Michaël Parmentier, UCLouvain, Louvain-la-Neuve, Belgium

Pascal Mallet, University Paris Nanterre, France

Bernard Rimé, UCLouvain, Louvain-la-Neuve, Belgium

This document is a post-review pre-publication version of the manuscript accepted for publication in International Journal for Educational and Vocational Guidance (https://www.springer.com/journal/10775). Please cite as:

Vignoli, E., Nils, F., Parmentier, M., Mallet, P., \& Rimé, B. (in press). The emotions aroused by a vocational transition in adolescents : Why, when, and how are they socially shared with significant others? International Journal for Educational and Vocational Guidance.

\footnotetext{
${ }^{1}$ Corresponding author : Emmanuelle Vignoli, Conservatoire National des Arts et Métiers, INETOP, 41, rue GayLussac, 75005 Paris, France, E-mail address: emmanuelle.vignoli@lecnam.net.
} 
The emotions aroused by a vocational transition in adolescents: Why, when and how are they socially shared with significant others?

\begin{abstract}
:
359 adolescents completed a self-report questionnaire that measured the emotional impact of an anticipated transition, social sharing modes, its psychological benefits, and relationships intimacy with mother, father and best friend. Results show that the transition has been shared rapidly, repeatedly, with several partners, especially intimates (mother, father, best friend). However, partners and motives of vocational sharing depend on the valence of the transition. The intensity of negative emotions is positively related to both the frequency and the depth of vocational sharing while the intensity of positive emotions is only related to the depth of the sharing. Perceived intimacy with significant others is positively associated with both the depth and the frequency of sharing, although to a lesser extent for the latter. In addition, the intrapersonal and interpersonal benefits are related to the depth of vocational sharing, but not to its frequency. The results are discussed in reference to knowledge and theories regarding the quality of relationships with significant others, emotions, social sharing of emotions in coping with vocational transitions and in career development. In particular, they show the importance of dissociating the frequency and depth of sharing in providing psychological benefits of social sharing and the importance to distinguish negative and positive emotions in this sharing process.
\end{abstract}

Keywords: vocational transition, social sharing, emotion, adolescence, intimate relationships 
The emotions aroused by a vocational transition in adolescents: Why, when and how are they socially shared with significant others?

According to Sharf (2013, p. 16), "Relationships with others affect almost everything that we do in our lives including our career development". To illustrate, he cites empirical work showing how attachment theory (e.g., Vignoli, 2009), the study of parent-child career interactions (e.g., Young et al., 2008), and Blustein's (2011) relational theory contribute to the understanding of career development processes. For adolescents more specifically, this line of reasoning is fueled by evidence that relationships with parents (Bryant, Zvontkovic, \& Reynolds, 2006; Dietrich \& Kracke, 2009), teachers, peers and friends (Di Fabio \& Kenny, 2015) influence critical vocational outcomes such as occupational knowledge, exploratory processes, career adaptability, career planning, etc. This article relies on the same perspective but, somehow, in a reverse direction. Rather than study the effect of adolescents social interactions on vocational outcomes, it focuses on the extent to which a vocational transition might bring an adolescent to develop social interactions. This kind of questioning is rooted in the research area on the social sharing of emotions (e.g., Rimé, 2009), assuming that a vocational transition, as an emotional event, will be socially shared in the environment. If this is verified, it is of primary importance to integrate into the field of vocational psychology the knowledge about the beneficial effects that the social sharing of emotions might generate in periods of transition. The psychosocial benefits of social sharing are based on theoretical arguments and empirical evidence (e.g., Rimé, 2005, 2009) but the conditions under which they occur and its processes need to be clarified, especially in the context of vocational events.

More precisely, the aim of this research is to answer the five following questions: (a) Do adolescents share vocational transitions with others? And if it is the case, (b) how, (c) with whom, (d) why and (e) for what anticipated benefits? Even if the three first questions have already resulted in research (Vignoli, 2011; Vignoli, Nils \& Rimé, 2005), they are rare and virtually nothing is known concerning the last two ones. The ambition here is to further examine the propensity to share a vocational transition according to the emotions it elicits, the sharing modalities and sharing targets, and to investigate why this social sharing occurs with such targets and what are the benefits adolescents associate with this vocational sharing. At a theoretical level, this should contribute to verify the role of social interaction elicitor played by emotions when facing a vocational transition and increase the understanding of adolescents' vocational social interactions, the aims pursued in these interactions and with which partners they think they will reach these aims. In terms of guidance practices, this could bring to counsellors indications about the socioemotional impact of a vocational transition during adolescence, the usual social behaviors of adolescents confronted with a transition, the people with whom they interact in transition situations and the acknowledged benefits of such interactions. More generally, given 
the potential benefits of the social sharing of emotions, such research can lead counsellors to encourage their clients to make greater use of their social network when faced with a vocational transition.

In the aforementioned references on the social sharing of vocational episodes (Vignoli, 2011; Vignoli et al., 2005), the logic behind the argument held in four steps: firstly, vocational transitions are important for individuals as they are associated with personal goals; secondly, events facilitating (vs. impeding) goal attainment induce emotions; thirdly, emotions stimulate social interactions. Fourthly, based on that reasoning, the authors transposed to the case of vocational social sharing the methods and findings related to the social sharing of emotion (e.g., Rimé, 2005, 2009), a more general and better-known phenomenon. Hereafter, we fully develop these four steps.

\section{Vocational transitions are associated with personal goals}

Following Nurmi and collaborators (Dietrich, Jokisaari, \& Nurmi, 2012; Nurmi, 2004; Nurmi, Salmela-Aro \& Koivisto, 2002; Vasalampi, Salmela-Aro, \& Nurmi, 2010), personal goals and vocational transitions are connected in a bi-directional way. Personal goals guide behavior when facing a transition, contribute to concentrate resources towards specific tasks inherent to the transition and serve for building strategies to cope with transitions. On the other hand, the result of a transition, in terms of goal (un)attainment, has implications for the way people reassess their goals. A successful transition might strengthen the importance of associated goals and self-efficacy beliefs towards future similar ones. At the opposite, failing in dealing with a transition may result in disengagement from previous goals and directing to other vocational trajectories. Empirical evidence upon interdependence between personal goals and vocational transitions have been reported for the specific case of transitions during adolescence, especially for the school to work transition (Nurmi et al., 2002) as well as during the transition from comprehensive to precomprehensive secondary education (Vasalampi et al., 2010), which is the specific transition investigated in this study.

\section{Events facilitating (vs. impeding) goal attainment induce emotions}

Referring in particular to Carver and Scheier (1990, 2001), Rimé (2009) stated that negative emotions occur when circumstances interfere with goal-reaching activities, while positive emotions result from circumstances facilitating them. At a deeper level of reasoning, as goal-reaching activities rely upon the capacity (1) to predict states of the world and the consequences of one's action, and (2) to control situations and to bring forth states of the world one had planned (Rimé, 2009), this presumes a large knowledge base (schemas, models of the world, implicit theories, core beliefs, ...) that could be, at least partially, invalidated in case of interfering events and therefore induce negative emotions, as anticipated by classic authors such as Cantril (1950) and Kelly (1955). On the contrary, for events facilitating goal-reaching activities, positive emotions are induced as the pursuit of a goal is substantially accelerated (Carver \& Scheier, 1990, 2001), proving that the subject's knowledge base is efficient and that his or her theories and models are supported. Said simply, as posited by Mandler (1984), two types of conditions can cause emotion: when 
something which was not expected occurs, or when something which was expected does not occur. Returning to the type of event under investigation in this article, this development fits nicely with the definition Schlossberg gave to vocational transitions: "A transition, broadly, is any event, or non-event, that results in changed relationships, routines, assumptions and roles" (Schlossberg, 2005, p. 27).

\section{Emotions stimulate social interactions.}

Schachter (1959) is considered the pioneer in the demonstration that exposition to (negative) emotional conditions elicits motivation to seek social contact. To explain this phenomenon, he endorsed a social comparison perspective, meaning that the search for social contacts in such emotional circumstances is mainly motivated by the need to compare to others in order to know how to react. Another relevant theoretical framework to shed light on the phylogenic roots of this propensity to seek social contact when experiencing negative emotion is provided by the classical research of Harlow and colleagues (e.g., Harlow \& Suomi, 1970) on nonhuman primate, showing that when infants are stressed by an unfamiliar event they turn out to their caregivers, suggesting that they try to use their appraisal to make sense of the event. This "social referencing" behavior was later observed in human too (Campos \& Stenberg, 1981; for a brief conceptual overview, see Holodynski, 2017). A similar meaning making function is attributed by Bruner (1990) to social communication, and especially narration, developed after emotional situations.

Rimé (1989) proposed the term "social sharing of emotion" to refer to the process of communicating in a socially shared language an emotional experience to another person. Since then, numerous studies using diverse methodologies (for a review, Rimé, Finkenauer, Luminet, Zech, \& Philippot, 1998), amply demonstrated that being exposed to an emotional event elicits a rapid and repetitive social sharing process addressed to several target persons. As confirmed by lab studies, the best predictor of the extent of sharing is the intensity of emotions aroused by the eliciting event (Berger, 2011; Luminet, Bouts, Delie, Manstead \& Rimé, 2000).

When questioning targets of social sharing, it has been consistently found that they are systematically part of the intimates' circle (Rimé, 2009). According to Laurenceau, Barrett and Pietromonaco (1998), the sharing of confidences and emotions, as well as the partner's reactions to those confidences, contributes to create and reinforce intimacy and trust between the two partners. On the other hand, intimacy is a component of attachment, and secure attachment facilitates the regulation of emotions by alleviating perceived depression or stress in transitions (Bowlby, 1978, 1982; Duchesne, Ratelle, Poitras, \& Drouin, 2009; Larose \& Boivin, 1998; Papini \& Rogman, 1992). It also fosters progress in career development (Blustein, Prezioso, \& PalladinoSchultheiss, 1995).

Concerning the target's choice among intimates, trends emerge as different age groups are compared (e.a. Rimé, Mesquita, Philippot, \& Boca., 1991). For both genders, attachment figures (father and mother) are the almost unique sharing targets in childhood. During adolescence, the best friend becomes an additional intimate partner, 
providing closeness, emotional support and self-validation (Booth-LaForce, \& Kerns, 2009; Buhrmester \& Prager, 1995). Mother, father and best friend could thus be potential targets with whom adolescents share a significant vocational event.

The last question addressed here about the social sharing of emotions concerns why it occurs. On the basis of Delfosse, Nils, Lasserre and Rimé (2004), and Duprez, Christophe, Rimé, Congard and Antoine (2014), seven different types of answers to the question: "why do we share emotional events?" can be given. These are rehearsing, venting, being supported, clarification seeking, looking for advice and solutions, arousing empathy/attention, self-worth and informing/warning. Delfosse et al. (2004) and Duprez et al. (2014) showed that positive events were shared more frequently for the reasons of re-experiencing the event, self-worth, informing others and arousing empathy and attention while the social sharing of negative events was more strongly associated with purposes like venting, seeking understanding, support, and advice.

If the reasoning so far is correct, it is possible to transpose findings from the social sharing of emotion research area to the specific case of vocational transitions. This leads to the six following hypothesis. (1) Adolescents share vocational transitions rapidly and repeatedly with several partners. (2) These partners are predominantly the mother, father and best friend. The extent of this vocational social sharing (frequency and depth) (3) depends on the intensity of emotions induced by the transition and (4) is positively related to the perceived intimacy with the sharing targets. (5) When the vocational event is positive, the sharing is likely to be intended to obtain self-validation through reciprocal empathy, and when the event is negative, the sharing is likely to be aimed at buffering the stress through social support and advises. (6) The frequency and depth of sharing are supposed to enhance the students' feelings of well-being concerning their academic and vocational future, in terms of both interpersonal (e.g., perception of social support) and intrapersonal (e.g., self-efficacy) benefits.

In order to test this set of hypotheses among an adolescent population, a normative educational transition, occurring in many countries, and for which the outcome can be quickly and clearly established, has been selected. It concerns the transition from comprehensive to pre-comprehensive secondary education. In France, where the present study took place, this transition happens at the end of the fourth year of secondary education. At that time, students are approximately 15 years old and they are all asked to state their intentions concerning their educational track until the end of secondary education. Three options are possible. Either they choose the academic track, leading to University and High School admission, the technical track, directing to technical higher education, or the vocational track, directly leading to the labor market. Shortly after, the class council gives a favorable, reserved or unfavorable advice upon the student's expressed intentions. If the advice is reserved, severe restrictions may impede early students' intentions while an unfavorable advice shut down access to the educational track desired by the student. It is important to note that this 
transition to pre-comprehensive secondary education is the first major transition for these French students and that the chosen (or enforced) educational track has strong implications on career paths.

Method

\section{Participants}

The participants were recruited in four publics middle-schools in the north and south of France. A total of 359 teenagers $(43.17 \%$ boys $)$ with a mean age of 14.98 years $(\mathrm{SD}=0.72)$ took part in this study. In their fourth year of secondary education, they were solicited by their school administration to participate to the research. Approximatively $43 \%$ of them were lower class, $34 \%$ were middle class and $23 \%$ were upper class. $31,5 \%$ of the parents of these adolescents had no diploma, 35,6\% held a professional degree or only an A-level degree, and 32,9\% had a degree superior to A-levels. All adolescents participated after obtaining parental consent. Among them, 71.03\% reported living with their two parents, $16.71 \%$ with their mother, $2.78 \%$ with their father and $5.85 \%$ with someone else. During the fifteen days following the class council advice, the vast majority of participants were in contact with their family and friends. Specifically, $95 \%$ of them were in contact with their mother, $87.50 \%$ with their father, $87.50 \%$ with their best friend, and $95.50 \%$ with their classmate.

\section{Procedure}

Fifteen days after the class council decision referred to in the introduction of this article, participants completed the questionnaire during a one-hour class and in the following order: biographical characteristics, characteristics of the vocational episode, perceived importance of the episode, induced emotions, vocational social sharing extent, partners, modalities, perceived benefits and motives, and intimacy with significant others. Participants were assured of the confidentiality of the results and debriefed once the questionnaires had been completed.

\section{Measures}

Features of the vocational episode. First, students were asked to express their primary educational project for the next years: which of the three possible tracks (academic, technical or vocational) did they want to follow? Next, they indicated if the class council had given a favorable, reserved or unfavorable advice upon their wish.

Emotions. The adolescents rated the emotions that they have felt when they received the decision of the class council. Their answers were collected on a seven-point scale from 1 (not affected at all) to 7 (very strongly affected) for the intensity of the felt emotion and on a six-point scale from -3 (very unpleasant) to 3 (very pleasant) for the emotional valence. In addition, using the Differential Emotional Scale (DES) from Izard and colleagues (1974), students rated on 5-point scales from 1 (not at all) to 5 (strongly), various emotions that they could have felt in the vocational episode. The specific emotions measured with the DES are interest, joy, sadness, anger, fear, anxiety, disgust, contempt, surprise, happiness, shame, guilt, and pride. This self-report scale is commonly used in studies for assessment of 
discrete emotional feelings (e.g., Gross \& Lenvenson, 1995; McHugo, Smith, \& Lanzetta, 1982; Philippot, 1993; Youngstrom, \& Green, 2003). Previous studies showed that the DES yielded a good discrimination of the majority of fundamental emotions (e.g., Fuenzalida, Emde, and Pannabecker, \& Stenberg, 1981; Philippot, 1993; Youngstrom, \& Green, 2003) and attest to the good validity of the scale. An exploratory factor analysis resulted in a two factors solution explaining $51.84 \%$ of the total variance. The first factor comprised negative emotions (sadness, anger, fear, anxiety, disgust, contempt and shame) while the second included positive ones (joy, happiness and pride). Guilt, interest and surprise had no satisfactory loadings and were removed from further analysis. As Cronbach alpha computed on the items from factor 1 and factor 2 respectively reached 0.86 and 0.84 , scores for negative and positive emotions were calculated.

Social sharing modalities. Relying upon previous work (Nils, 2003; Rimé, 2005, Vignoli et al., 2005; Vignoli, 20011), we asked respondents to specify the way they shared the vocational episode with their social environment. The sharing partners were identified using a dichotomous scale (yes / no) (Have you discussed with ...?). Potential partners proposed were the mother, father, best friend, at least one sister and brother (if they had one), at least one teacher, a guidance counselor or any other person (participants had the opportunity to mention non-listed potential partners). The delay between the onset of the vocational episode and the first sharing was assessed for each potential partner with a response scale with four alternatives ("on the same day", "on the day after", "two to seven days later "," more than one week later "). The frequency of social sharing with each partner was assessed using a Likert scale with responses ranging from "one time" to "eight or more times". Additionally, as the type of content shared (e.g., facts, emotions, thoughts) may have a crucial role with respect to the psychological effects of the social sharing (Rimé, Finkenauer, Luminet, Zech \& Philippot, 1998), a shared content scale was developed to take into account these elements. A 13 items questionnaire was used, with Likert scales ranging from 1 (not at all) to 5 (strongly). For each of the three major potential partners of vocational sharing, this questionnaire examined the extent to which participants talked about their felt emotions regarding the vocational episode, their current and future vocational situation, and the details of the episode, its meaning and their occupational future. One of the 13 items was found poorly correlated with the other ones and was dropped. The internal consistency of the total scale assessed using Cronbach's alpha was very satisfying for every partners: mother (.81), father (.81) and best friend (.84). Three scores of shared content depth have thus been calculated. A high score means a high depth of social sharing.

Motives for the vocational sharing. The perceived reasons why adolescents shared the vocational event were assessed with a 25-item scale adapted from Delfosse et al. (2004) and Duprez et al. (2014). It comprises the following seven categories of sharing reasons: clarification and meaning making; relive or remember the emotion; reduce the emotional load associated with the vocational episode; induce attention and empathy from others; Self-worth, inform and warn 
others; seeking for support, comfort and solace; seeking for advice, guidance and solutions. These different motives for social sharing were associated with the valence of the emotional experience (Delfosse et al., 2004; Durez et al., 2014). For each item, participants rated on a five points scale ranging from 1 (not at all) to 5 (totally agree) the extent to which each specific motive for sharing led them to share actually with each partner. With no exception, Cronbach's alpha computed on the items of each category exceeded the threshold of .70 and three were over .80 . Perceived intrapersonal and interpersonal benefits. At the time of the investigation, fifteen days after the advice notified by the class council, and therefore after a period during which the verbalization process of the episode occurred, respondents rated on several intrapersonal and interpersonal dimensions their well-being concerning their academic and vocational future. They indicated on five-point scales ( 1 "not at all" to 5 "completely") to what extent they felt "supported by those around them," "relieved, released", "understood", "having on hand all the elements to deal with the situation", "reassured", "better understanding what is going on ", and "less alone". The goal here was to measure perceived benefits that might have resulted from the social sharing process. Experimental investigation conducted by Zech and Rimé (2005) had indeed revealed that in the days or weeks following a social sharing situation, participants reported a variety of perceived benefits including (1) interpersonal benefits (support, understanding by the surroundings, reduction of feelings of loneliness) and (2) intrapersonal benefits (relief, feeling of being able to cope with the situation, reinsurance, better understanding of the episode). A factor analysis from the responses to these seven items resulted in a two factor solution, with the interpersonal benefits items concentrating on one of them and the intrapersonal benefits on the other. Cronbach alpha computations revealed a good internal consistency for the interpersonal benefits dimension (.70) and the intrapersonal benefits dimension (.77). Two scores were thus calculated. Intimacy with significant others. Intimacy with each of the three main expected social sharing targets--father, mother and best friends-- was assessed using the French version of the intimacy scale developed by Hunter and Youniss (1982). This four-items scale addressed respectively companionship, self-disclosure, empathy, and consensus formation (e.g., “He/she usually knows how I feel.”). In consistence with previous studies (e.g., Kon and Losenkov, 1978), in the study by Hunter and Youniss (1982), the friend was reported provided the most intimacy, followed by mother, and last by father, and attests to the reliability of this scale. In line with cross-cultural translation procedures (Brislin, 1986; Vallerand, 1989), the original intimacy scale was translated into French by the first author and was then back translated into English by a native speaker of English who is an expert in the field. The differences between the original version and the French version were checked and corrected. Participants responded on a 4-point scale from 1 (rarely) to 4 (almost always). A high score indicates a high level of intimacy with the respective partner. In the study by Hunter and Youniss (1982), the alpha values for the intimacy total scores were .72, .74 and .71 for father, mother and friend, respectively. In the present sample, Cronbach's alphas reached respectively $.77, .80$, and .85 . 


\section{Data analyses}

In order to test our research questions and hypotheses, we adopted a 4-step strategy. At step 1, we first performed descriptive analyses of the features of the vocational episode, the importance of the class council advice and the emotional impact of the vocational episode. At step 2, we performed several univariate statistical analyses in order to test the hypotheses of our first research question related to the extent, frequency, delay, targets, emotions, and motives of the vocational sharing and compare the modalities of vocational sharing according to the class council advice (i.e., favorable versus unfavorable). In order to test the hypotheses related to our second research question corresponding to step 3, we first performed confirmatory factor analyses in order to assess the measurement validity of the latent constructs of interest, namely emotions, intimacy with significant others, depth of the shared content, perceived intrapersonal and interpersonal benefits of vocational sharing. At step 4, we performed several path analyses in order to test the structural relations hypothesized in Research Question 2 related to the influence of emotions and intimacy on the frequency and depth of the content of vocational sharing and on the perceived intrapersonal and interpersonal benefits of vocational sharing. Those path analyses were multigroup in order to assess the differences between students having received a favorable advice and those having received an unfavorable advice from the class council. All statistical analyses were performed using SPSS 24 and MPlus 8.

$$
\text { Results }
$$

\section{First step. Descriptive statistics}

Features of the vocational episode. Adolescents' intentions regarding their educational future were distributed as follows: $79.5 \%$ wished to enroll in the academic or technological track; $20.2 \%$ wished to move towards a vocational track and $0.3 \%$ were repeat already one school year. Most students received a favorable advice from the class council $54.9 \%(n=196), 27.7 \%(n=99)$ received a reserved advice that is to say an advice giving a cautious welcome to the adolescents' intentions regarding their educational future, and $17.4 \%(n=62)$ an unfavorable advice. In total, $44.85 \%$ were notified that the class council did not fully supported their future intentions, while the others received completely favorable advices. In further analyzes we will consider these two groups, each representing about half of the total sample. A chi-square independence test revealed no significant difference in proportions between boys and girls for that variable $\left(\chi^{2}(1)=1.98, p=.16\right)$.

The importance of the class council advice. The vast majority of participants $(71.8 \%)$ considered the class council advice as important or very important, $16.6 \%$ gave it a moderate importance and $11.6 \%$ little or low importance. A $t$ test evidenced a marginal tendency to attribute a higher value to a favorable $(M=3.94, S D=1.02)$ than to an unfavorable advice $(M=3.73, S D=1.16), t(352)=1.81, p<.10$. 
Emotional impact of the vocational episode. Strong differences are observable concerning emotions depending on the decision of the class council. Compared to an unfavorable advice, a favorable advice is associated with more positive emotions $(t(356)=13.85, \mathrm{p}<.001)$, less negative emotions $(t(356)=-10.52, \mathrm{p}<.001)$, and less global emotional intensity $(t(356)=-6.77, \mathrm{p}<.001)$ advice.

\section{Second step. Research question 1}

Extent, frequency, delay and targets of the social sharing. With the exception of 4 participants, all students shared the vocational episode during the fifteen days following the class council decision. As can be seen in Table 1, this vocational sharing was higher with intimates (i.e., mother, father, and best friend) than with other members of the entourage (e.g., brother and sisters, teachers, and counselor). Chi-square independence tests revealed that students tended to share less with their mother and father when the class council advice was unfavorable $\left(\chi^{2}(1)=5.36, p<.05\right.$ for the mother; $\chi^{2}(1)=12.51, p<.001$ for the father). On the contrary, students tended to share more with a teacher or a counselor when the class council advice was unfavorable $\left(\chi^{2}(1)=16.56, p<.001\right.$ for the teacher; $\chi^{2}(1)=6.59, p<.04$ for the counselor). Vocational sharing with other members was the same regardless of the class council advice. Concerning the delay between the class council decision and the first social sharing, it appears that it is shared very rapidly, at least with intimates. It is shared the day of the notification with the mother in $65 \%$ of the cases, with the father in $45.3 \%$, and with the best friend in $44 \%$. After two days, it has been shared with the mother in $84.4 \%$ of the cases, with the father in $71.9 \%$, and with the friend in $84.7 \%$. Delays are longer for the other sharing targets. To the extreme, $60.3 \%$ of the adolescents who shared the vocational episode with a counselor did it more than one week after it happened. Interestingly, no significant differences were found when comparing delays of vocational sharing following a favorable to delays after an unfavorable class council advice. Regarding the frequency with which the vocational episode is shared, only a minority of the participants shared only once with their intimates $(26.9 \%$ with their mother, $43.3 \%$ with their father, $35.1 \%$ with a friend). Actually, they shared the vocational episode repetitively (i.e., from two to six times) with their mother in $60.9 \%$ of the cases, with their father in $52 \%$, and with their friend in $57.2 \%$. When using average frequency, results showed that it was shared more frequently with the mother following an unfavorable advice $(M=3.62, S D=2.33)$ than a favorable advice $(M=2.77, S D=1.99), t(318)=-3.50, p<.01)$. It was also shared more frequently with the best friend following an unfavorable advice $(M=3.15, S D=2.17)$ than following a favorable advice $(M=2.44, S D=1.79), t(269)=-2.95, p<.01)$. However, no differences in frequency of sharing was found for the father $(t(252)=-1.64, p=.10)$. One single social sharing was observed in majority with other persons (with a counsellor in $79.7 \%$ of the cases, with a teacher in $58.5 \%$, a brother in $57.8 \%$ and a sister in $51.9 \%$ ), regardless of the class council advice.

[Insert table 1] 
Motives for social sharing. The third hypothesis stated that the motives of the social sharing would differ according to the valence of the school council decision. Seven classes of reasons for social sharing have been measured. In table 2 , the importance accorded to these reasons are reported in function of the valence of the school council decision. As expected, clarification and meaning making, reduction of the emotional load and support and comfort seeking are more reported for an unfavorable council decision. At the opposite, informing, warning others and in a lesser extent selfworth $(p=.06)$ are more frequently alleged in case of a favorable class council decision.

[Insert Table 2]

\section{Third step. Research question 2}

Confirmatory factor analyses. We conducted CFAs to examine the distinctiveness of the constructs included in the analyses of our second research question (i.e., positive and negative emotions, perceived intimacy with significant others, depth of the shared content, and perceived intrapersonal and interpersonal benefits of vocational sharing). As the constructs of perceived intimacy with significant others and depth of the shared content were measured for each of the three main targets of vocational sharing (i.e., mother, father, best friend), our full measurement model included 10 different latent constructs. The analyses showed that this 10 -factor model fitted the data well $\left(\chi^{2}(1400)=2182.29\right.$; $\mathrm{RMSEA}=.04 ; \mathrm{CFI}=.91 ; \mathrm{TLI}=.90 ; \mathrm{SRMR}=.08)$ and was significantly superior to all more constrained models. For the two constructs that were measured for each main target of vocational sharing, error terms across targets were free to correlate as they shared common method variance due to their similar item wording. All indicators loaded reliably on their latent constructs, with standardized loadings ranging from .74 to .84 for positive emotions, from .55 to .81 for negative emotions, from .59 to .88 for perceived intimacy, from .37 to .69 for depth of the shared content, from .60 to .74 for intrapersonal benefits, and from .59 to .81 for interpersonal benefits. In the subsequent analyses, separate path analyses have been favored over full structural equation analyses due to the complexity of our hypothesized model and in order to finely assess the differences according to the target of vocational sharing and to the valence of the vocational episode.

\section{[Insert Table 3]}

\section{Fourth step. Research question 2}

Multigroup path analyses. In order to test the specific hypotheses related to our second research question, we fitted $3 \times 2$ multigroup path models for the three main targets of vocational sharing. In each model, two groups were compared (i.e., favorable versus unfavorable advice) in order to assess the differences according to the valence of vocational episode. For each target (i.e., mother, father, and best friend), two different models were fitted (i.e., a baseline and a constrained model; see Table 3) in order to test whether the class council decision moderated the structural relationships hypothesized in our models. This analytical strategy consisted of nested model comparisons informing whether a 
constrained model, imposing the equality of parameters between those with a favorable advice and those with an unfavorable advice yielded a significant decrease in model fit compared to the freely estimated model. In the baseline model, structural relationships were allowed to differ across the two groups, while, in the constrained model, structural relationships were constrained to be equal across the two groups. As no significant differences were found when constraining the structural relationships between the two groups, our results showed that the class council advice did not moderate the structural relationships in our models. Therefore, the models constraining all structural relationships to be equal between those having received a favorable and those an unfavorable advice were retained as the best descriptions of our data. The parameters estimates of these models are displayed in Figure 1, 2, and 3.

\section{[Insert Figure 1]}

Regardless of the valence of the class council decision, our results showed that negative emotions were systematically related to both the frequency and the depth of vocational sharing while positive emotions were associated to the depth of the shared content. Except for the best friend, emotional intensity was not related to either the frequency or the depth of vocational sharing. Overall, perceived intimacy was more closely related to the depth than to the frequency of the sharing, regardless of the valence of the council decision. In average across the targets, those variables accounted for $11.3 \%$ and $21.3 \%$ of the variance of the frequency of vocational sharing and the depth of the shared content, respectively.

\section{[Insert Figure 2]}

With regard to the perceived benefits of vocational sharing, results showed that only the depth of sharing was related to both intra- and interpersonal benefits while the frequency of sharing was not predictive of the perceived benefits, except for the best friend with which frequency of sharing was marginally related to interpersonal benefits of sharing. Those results did not differ in function of the valence of the class council decision. In average across the targets, frequency and depth of sharing accounted for $5.7 \%$ and $8.3 \%$ of the variance of inter- and intrapersonal benefits, respectively.

\section{[Insert Figure 3]}

\section{Discussion}

The reasoning underlying this study can be summarized as follows: if a vocational transition such as the transition to post-comprehensive school (and the class council advice on the school track chosen by an adolescent) elicits emotions, this vocational transition must elicit a social sharing process. Therefore, the typical characteristics of the social sharing of emotions (extent, delay, targets, reasons, perceived benefits) should apply. This reasoning led us to examine six hypotheses.

As a first step (hypothesis 1), it was stated that vocational transitions are socially shared with others. Looking at the research results leave no doubt on that issue. The vocational transition under the scope, consisting in receiving the decision from the class council concerning the choice for future orientation at school, has been socially shared by 
almost $100 \%$ of the adolescents. Moreover, it has been shared very rapidly, very often for several times and with several partners, especially with intimates (mother, father and best friend), confirming the second hypothesis.

Supporting our second hypothesis and in line with previous studies (Vignoli et al., 2005), results showed that both positive and negative experiences regarding a vocational transition trigger a social sharing process, particularly with significant others. As expected, the parents and best friend were clearly the most solicited persons and in a short time. Previous studies documented the significant role of adolescent's relationships with parents in the vocational maturation process, and the importance of the quality of attachment in this respect (e.g. Blustein et al., 1995; Ketterson \& Blustein, 1997; Schultheiss \& Blustein, 1994). Regarding the role of friendship, previous research is scarce.

Nevertheless, our results support Hunter's (1985) seminal findings while nuancing them. On the one hand, they confirm the decisive role of parents in social interactions about a vocational event with their 15 years old teenager. On the other hand, it appears that best friends are, at that age, about as important for this kind of interaction. It contrasts slightly with Hunter, who observed that such interactions between young people became as important as those with parents a little later, around the age of 18. Many adolescents are worried to disappoint their parents with respect to academic and career achievement (Vignoli \& Mallet, 2012). Therefore, the opportunity to talk openly and freely may account for the high proportion of adolescents who shared the vocational event with their best friend, the latter being especially able to understand the worries and hopes elicited by such kind of vocational event. This finding is in line with the well-known function of close friendship as an optimal way for self-clarifying disclosure during adolescence (Buhrmester \& Prager, 1995).

According to the third hypothesis, the extent of the vocational social sharing, both in terms of frequency and depth, should be a function of the intensity of emotions induced by the transition episode. Again, the results are quite clear and confirm previous studies on the social sharing of emotions (Berger, 2011; Luminet et al., 2000). However, two new and interesting elements are brought here as classical data on the link between emotion intensity and extent of sharing dealt generally with negative emotions and frequency of social sharing. Here, these findings are replicated, but we also provide evidence concerning positive emotions and the depth of the social sharing. Indeed, the intensity of negative emotions elicited by the vocational event is related to both the frequency and depth of social sharing (to a lesser extent for the father) while positive emotions are only related to the depth of the shared content (except for social sharing with the best friend). Two characteristics distinguish negative and positive emotional experiences regarding vocational event. Firstly, vocational negative experiences are perceived as more emotionally intense than vocational positive experience (Vignoli et al., 2005, 2011). And the more the emotional experiences are strong, the more they are shared (Rimé et al., 1998). Secondly, negative emotions occur when the pursuit of a goal is slowed down, or blocked while positive emotions facilitate goal-reaching activities (Rimé, 2009). In addition, negative emotions disconfirm 
models of reality, lead to a loss of meaning, weakened self-esteem, identity and increase anxiety and feelings of insecurity. Positive emotions consolidate self-efficacy and self-esteem, strengthen well-being, and support the subject's models. For these reasons, it can be hypothesized that both the frequency and depth of social sharing of emotions are necessary for the resorption of negative emotional experience through the restoration of meaning, models, and subject's reassurance while a thorough sharing, without repetition, seems sufficient for the processing of a positive emotional experience.

Supporting the fourth hypothesis, the extent of sharing (frequency and depth) with the three major sharing targets depends on the perceived intimacy with each of them. More specifically, even if the frequency of sharing is significantly associated with perceived intimacy, the strongest links have been found for the depth of sharing, whether with the mother, father or best friend. This suggests that the likelihood to discuss and debrief profoundly such life event with close partners depends on the quality of the specific relationships. This kind of result confirms that the quality of the relationship with significant others in a young people's life play an important role on transition processes and career related outcomes (Young et al., 2008). Concerning the parents more specifically, our observations echo Young et al. (2008) results based upon their analysis of parent-youth interactions related to the transition to adulthood. They showed that projects like career promotion of young people are embedded in the parent-youth relationship and depend on its quality. These results are also consistent with previous studies showing the quality of parent-adolescent relationships facilitate career development and identity formation regarding career development (e.g., Blustein, Wallbridge, Friedlander, \& Palladino, 1991; Grotevant \& Cooper, 1985; Kenny, 1990; Palmer \& Cochran, 1988).

The fifth hypothesis stated that the alleged reasons for the vocational sharing depend on the valence of the transition issue. Consistently with previous research (Delfosse et al., 2004; Duprez et al., 2014), the motives for sharing the unfavorable class council decision are more oriented towards search for meaning, clarification, efforts at understanding what had happened, and search for support and comfort from intimate partners. Although it is a belief, sharing in order to reduce the emotional load is also more frequently mentioned by adolescents facing a vocational negative event. Conversely, the main motives for sharing a positive vocational event are to inform and warn others, and in a lesser extent to value oneself. As mentioned above, positive emotional experiences facilitate reaching goals and reinforce self and positive beliefs (Carver \& Scheier, 1990; Rimé, 2009). The main reason for sharing a positive vocational experience is to amplify pleasant experience and to consolidate individual identity and the well-being (Delfosse et al. 2004; Gable, Reis, Impett \& Asher, 2004). Conversely, negative emotional experiences alter implicit positive beliefs about the world, weaken self-esteem and sense of self-efficacy (e.g., Janoff-Bulman, 1992; Rimé, 2005, Rimé et al., 1992). Important reasons for sharing vocational negative event with close partners may be to reduce the cognitive dissonance between one's own expectations, representations and the perceived reality, or in order to find 
social support, to be reassured, and to better cope with his vocational future (Rimé et al., 1992; Thoit, 1984). Sharing negative emotional experiences strengthens relationships with partners, and helps to reduce perceived stress and to increase self-esteem (eg., Bowlby, 1978, 1982; Duchesne, Ratelle, Poitras, \& Drouin, 2009; Laurenceau, Barrett and Pietromonaco,1998; Papini \& Rogman, 1992). According to Thompson and Janigian (1988), through the autobiographical construction, life scheme allows restoration of meaning, especially when negative emotional experiences challenge the representations of the world and of oneself.

According to the sixth and last hypothesis, the frequency and depth of sharing were expected to be positively related to beneficial outcomes. On the basis of our results, the frequency of sharing is not associated with perceived benefits, whether at the interpersonal or intrapersonal level, while the depth of sharing, regardless of the intimate target, is associated with both interpersonal and intrapersonal perceived benefits. This result on the frequency of social sharing is consistent with observations from other studies (Curci \& Rimé, 2012; Rose, 2002) that show that repetition of social sharing is not associated with benefits and is sometimes even linked to an increase in emotional distress. Moreover, our results reinforce the view that frequency and depth of sharing have to be disentangled, because these two aspects of the extent of sharing were differently associated to beneficial outcomes. According to Nils and Rimé (2012), the benefits of social sharing are largely determined by the modalities of interaction between its partners: only a social sharing associated with a cognitive treatment of the event can lead to benefits related to its emotional load. This most likely implies that this social sharing is carried out in depth.

To sum up, the vocational transition between comprehensive to pre-comprehensive secondary education, and the advice given by a class council concerning the educational track chosen by an adolescent student, elicits emotions. As such, this transition is socially shared by the adolescents, especially with significant others (mother, father and best friend), at an amplitude (frequency and depth) determined by the intensity of the positive and negative emotions it has induced. The reasons alleged for this social sharing depend on the valence of this vocational event. Along with the intensity of the emotions felt, the frequency and depth of social sharing are also associated with the degree of intimacy between the adolescent and his/her sharing targets. This is especially observable for the depth of sharing, confirming that the quality of the relationships with these targets play an important role in dealing with this kind of transition. And this is particularly true, given that the depth of social sharing is associated with both perceived interpersonal and intrapersonal benefits. In addition, intentionally, the instructions were not specifically direct the participants to relate the perceived intrapersonal and interpersonal benefits to the vocational sharing of emotions. If we had done so, the link between the two variables would have probably been biased, confirming the hypothesis. Therefore, perceived psychological benefits may be related to variables other than social sharing regarding the academic and vocational 
future. It is probable that the relationship observed in this study between perceived intrapersonal and interpersonal benefits and social sharing of emotions is less strong than it would be without the presence of these variables.

Although the results of this study are unambiguous, the cross-sectional nature of its design prevents us from verifying the causal direction of the links between the variables under investigation. In line with the work of Young et al. (2008) and Nils and Rimé (2012), this is particularly true for intimate relationships which can be both the cause and the consequence of verbalization processes. It is therefore possible that the specific social sharing we investigated, focusing on one aspect of a young person's career development, have enhanced intimacy between its interlocutors. We must therefore consider the present study as an attempt to apply the theories related to the phenomenon of the social sharing of emotions to a vocational transition, in need for further evidence using experimental or longitudinal designs to verify in a more rigorous way the causal paths pointed here. Another possible limitation of this research relates to the fact that we only observed face-to-face social sharing, while adolescents are particularly eager to communicate through social media. Two reasons have led us to neglect online social sharing. Firstly, a comprehensive review (Derks, Fisher $\&$ Bos, 2008) shows that, despite the presence of visual and written cues, emotional communication online and offline is quite similar. Secondly, models and methodological tools of online social sharing is still in need for development (Rimé, Bouchat, Paquot \& Giglio, 2019). Finally, another limit of this study is that some scales may be related to social desirability. In future studies, it would be informative to measure social desirability in order to obtain a rigor assessment of others scales.

Despite these limitations, this study makes an important contribution to existing theory and research, as well as for practice. On the one hand, our observations confirm, in line with Hartung (2011), the need to take into account the emotional aspects related to vocational processes, both as a consequence of vocational events and as a source for action. On the other hand, they also confirm the importance of interactions with relatives in periods of transitions. More specifically, the quality of parent-youth relationships is again highlighted as an important vector in the career development process of young persons. Once more, this study attests to the very general and highly applicable nature of the characteristics of the social sharing of emotions, in terms of its extent, delay, sharing targets, reasons given for sharing and its perceived benefits. This point could encourage research of the same type but about other vocational transitions. Other research could also be taken further by using more appropriate methodologies to establish causal links between the features of the sharing process, its outcomes and its individual and environmental predictors. On a more practical level, we note that the social sharing of a vocational transition with parents and friends during teenagerhood is normal and adaptive, in view of the benefits it generates. This observation must be recognized in the community of practitioners, who could therefore encourage such interactions. In addition, in times of transitions, the counselor might help to deepen this work, especially when adolescents do not receive social support from their significant others 
(Savickas \& Pouyaud, 2016). However, two additional conditions seem to have to be met for these benefits to be realized. As mentioned earlier, it is important to have a deep social sharing rather than a repetitive one. And this first condition is based on a second: the good quality of relationships between the sharing partners. Thus, in the French educational system, which guides vocational choices at an early age, the results of this study highlight the inequalities in social support available to adolescents to cope with a vocational transition, specifically when it arouses negative emotions. 


\section{References}

Berger J. (2011). Arousal increases social transmission of information. Psychological Science, 22, 891-893. https://doi.org/10.1177/0956797611413294

Blustein, D. L. (2011). A relational theory of working. Journal of Vocational Behavior, 79, 1-17. https://doi.org/10.1016/j.jvb.2010.10.004

Blustein, D.L., Prezioso, M.S., \& Palladino Schultheiss, D. (1995). Attachment theory and Career Development. Current Status and Future Directions. The Counseling Psychologist, 23, 416-432. https://doi.org/10.1177/0011000095233002

Blustein, D.L., Wallbridge, M.M., Friedlander, M.L., \& Palladino, D.E. (1991). Contributions of psychological separation and parental attachment to career development process. Journal of Counseling Psychology, 38, 39-50. http://dx.doi.org/10.1037/0022-0167.38.1.39

Booth-LaForce, C., \& Kerns, K.A. (2009). Child-parent attachment relationships, peer relationships, and peer-group functioning. In K.H. Rubin, W.M. Bukowski, \& B. Laursen (Eds.), Handbook of peer interactions, relationships, and groups (pp. 490-507). New York: Guilford.

Bowlby, J. (1978). Attachement et perte: Vol 1. l'attachement [Attachment and loss: Vol 1. Attachment] (2nd ed.). Paris: PUF.

Bowlby, J. (1982). Attachment (2nd ed.). New York: Basic Books.

Boyle, J.G. (1984). Reliability and validity of Izard's Differential Emotions Scale. Personality and Individual Differences, 5, 747-750.

Brislin, R. W. (1986). The wording and translation of research instruments. In W. Lonner, \& J. Berry (Eds.), Fields methods in cross-cultural research (pp.137-164). Beverly Hills, CA: Sage.

Bruner, J. (1990). Acts of meaning. Cambridge, MA: Harvard University Press.

Bryant, B. K., Zvontkovic, A. M., \& Reynolds, P. (2006). Parenting in relation to child and adolescents' vocational development. Journal of Vocational Behavior, 69, 149-175. https://doi.org/10.1016/j.jvb.2006.02.004

Buhrmester, D., \& Prager, K. (1995). Patterns and functions of self-disclosure during childhood and adolescence. In K. J. Rotenberg (Ed.), Cambridge studies in social and emotional development. Disclosure processes in children and adolescents (pp. 10-56). New York, NY, US: Cambridge University Press. http://dx.doi.org/10.1017/CBO9780511527746.002

Campos, J. J., \& Stenberg, C. (1981). Perception, appraisal, and emotion: The onset of social referencing. In M. E. Lamb \& L. R. Sherrod (Eds.), Infant social cognition: Empirical and theoretical considerations (pp.273-314). Hillsdale, NJ: Erlbaum. 
Cantril, H. (1950). The why of man's experience. New York: MacMillan.

Carver, C. S., \& Scheirer, M. F. (1990). Origins and functions of positive and negative affect: A control-process view. Psychological Review, 97, 19-35. http://dx.doi.org/10.1037/0033-295X.97.1.19

Carver, C. S., \& Scheirer, M. F. (2001). On the self-regulation of behaviour. Cambridge: Cambridge University Press.

Curci, A., \& Rimé, B. (2012). The temporal evolution of social sharing of emotions and its consequences on emotional recovery: A longitudinal study. Emotion, 12, 1404-1414. http://dx.doi.org/10.1037/a0028651

Delfosse, C., Nils, F., Lasserre, S., \& Rimé, B. (2004). Les motifs allégués du partage social et de la rumination mentale des émotions comparaison des épisodes positifs et négatifs [Alleged motives for social sharing and mental rumination of emotions : A comparison of positive and negative episodes]. Les cahiers internationaux de psychologie sociale, 4, 35-44.

Derks, D., Fisher, A. H., \& Bos, A. E. (2008). The role of emotion in computer-mediatied communication: A review. Computers in Human Behavior, 24, 766-785. https://doi.org/10.1016/j.chb.2007.04.004

Di Fabio, A., \& Kenny, M. E. (2015). The contributions of emotional intelligence and social support for adaptive career progress among Italian youth. Journal of Career Development, 42, 48-59.

https://doi.org/10.1177/0894845314533420

Dietrich, J., \& Kracke, B. (2009). Career-specific parental behaviors in adolescents' development. Journal of Vocational Behaviour, 75, 109-119. https://doi.org/10.1016/j.jvb.2009.03.005

Dietrich, J., Jokisaari, M., \& Nurmi, J. E. (2012). Work-related goal appraisals and stress during the transition from education to work. Journal of Vocational Behavior, 80(1), 82-92. https://doi.org/10.1016/j.jvb.2011.07.004

Duchesne, S., Ratelle, C.F., Poitras, S.C., \& Drouin, E. (2009). Early adolescent attachment to parents, emotional problems, and teacher-academic worries about the middle school transition. Journal of Early Adolescence, 29, 743-766. https://doi.org/10.1177/0272431608325502

Duprez, C., Christophe, V., Rimé, B., Congard, A., \& Antoine, P. (2015). Motives for the social sharing of an emotional experience. Journal of Social and Personal Relationships, 32, 757-787.

https://doi.org/10.1177/0265407514548393

Fuenzalida, C., Emde, R.N., and Pannabecker, B.J., \& Stenberg, C. (1981). Validation of the Differential Emotions Scale in 613 Mothers. Motivation and Emotion, 5, 37-45.

Gable, S. L., Reis, H. T., Impett, E.A., \&Asher, E. R. (2004). What do you do when things go right? The intrapersonal and interpersonal benefits of sharing positive events. Journal of Personality and Social Psychology, 87, 228245. http://dx.doi.org/10.1037/0022-3514.87.2.228 
Gross, J.J. \& Levenson, R.W. (1995). Emotion Elicitation Using Films. Cognition \& Emotion, 9, 87-108. https://doi.org/10.1080/02699939508408966

Grotevant, H.C., \& Cooper, C. (1985). Patterns of interaction in family relationships and the development of identity exploration in adolescence. Child Development, 56, 415-428. https://doi.org/10.4324/9781315827063

Harlow, H.F., \& Suomi, S.J. (1970). Nature of love: Simplified. American Psychologist, 25, 161-168. http://dx.doi.org/10.1037/h0029383

Hartung, P.J. (2011). Barrier or benefit? Emotion in life-career design. Journal of Career Assessment, 19, $296-305$. https://doi.org/10.1177/1069072710395536

Holodynski, M. (2017). Comment: Reframing the conceptual diversity of social appraisal and social referencing. Emotion Review, 9, 265-267. https://doi.org/10.1177/1754073916669598

Hunter, F.T. (1985). Adolescents' perception of discussions with parents and friends. Developmental Psychology, 21, 433-440. http://dx.doi.org/10.1037/0012-1649.21.3.433

Hunter, F. T., \& Youniss, J. (1982). Changes in functions of three relations during adolescence. Developmental Psychology, 18, 806-811. http://dx.doi.org/10.1037/0012-1649.18.6.806

Izard C. E., Dougherty F. E., Bloxom B. M. and Kotsch N. E. (1974). The Differential Emotions Scale: a Method of Measuring the Subjective Experience of Discrete Emotions. Vanderbilt University Press: Nashville, Tenn.

Janoff-Bulman R. (1992). Shattered assumptions: towards a new psychology of trauma. New York: Free Press. https://doi.org/10.1080/00029157.1994.10403078

Kelly, G. A. (1955). A theory of personality: A psychology of personal construct. New York: Norton.

Kenny, M.E. (1990). College's senior perception of parental attachments: The value and stability of family ties. Journal of College Student Development, 31, 39-46.

Ketterson, T.U. \& Blustein, D.L. (1997). Attachment Relationships and the Career Exploration Process, Career Development Quarterly, 46, 167-178. doi :10.1002/j.2161-0045.1997.tb01003.x.

Larose, S. \& Boivin, M. (1998). Attachment to parents, social support expectations, and socioemotional adjustment during the high school-college transition. Journal of Research Adolescence, 8, 1-27.

Laurenceau, J. P., Feldman Barrett, L., \& Pietromonaco, P. R. (1998). Intimacy as an interpersonal process: The importance of self-disclosure, partner disclosure, and perceived partner responsiveness in interpersonal exchanges. Journal of Personality and Social Psychology, 74, 1238-1251.

Luminet, O., Bouts, P., Delie, F., Manstead, A. S., \& Rimé, B. (2000). Social sharing of emotion following exposure to a negatively valenced situation. Cognition \& Emotion, 14, 661-688. https://doi.org/10.1080/02699930050117666 
McHugo,G.J., Smith, C.A., \& Lanzetta, J.T. (1982). The Structure of self-reports of emotional responses to Film Segments. Motivation \& Emotion, 6, 365-385.

Mandler, G. (1984) Mind and body: Psychology of emotion and stress. New York Norton.

Nils, F. (2003). Le partage social des émotions déterminants interpersonnels de l'efficacité de la communication des épisodes émotionnels. [The social sharing of emotions: interpersonal determinants of the efficacy of emotional episodes' communication]. Unpublished doctoral dissertation, Université Catholique de Louvain, Louvain, Belgique.

Nils, F., \& Rimé, B. (2012). Beyond the myth of venting: Social sharing modes determine the benefits of emotional disclosure. European Journal of Social Psychology, 42, 672-681. https://doi.org/10.1002/ejsp.1880

Nurmi, J. E. (2004). Socialization and self-development: Channeling, selection, adjustment and reflection. In R. Lerner \& L. Steinberg (Eds.), Handbook of adolescent psychology (pp. 85-124). New York: Wiley.

Nurmi, J. E., Salmela-Aro, K., \& Koivisto, P. (2002). Goal importance and related achievement beliefs and emotions during the transition from vocational school to work: Antecedents and consequences. Journal of Vocational Behavior, 60, 241-261. https://doi.org/10.1006/jvbe.2001.1866

Palmer, S. \& Cochran, L. (1988). Parents as agents of career development. Journal of Counseling Psychology, 35, 7176. http://dx.doi.org/10.1037/0022-0167.35.1.71

Papini, D. R., \& Rogman, L. A. (1992). Adolescent perceived attachment to parents in relation to competence, depression and anxiety: A longitudinal study. Journal of Early Adolescence, 12, 420-440. https://doi.org/10.1177/0272431692012004005

Philippot, P. (1993). Inducing and assessing differentiated emotion-feeling states in the laboratory. Cognition \& Emotion, 7, 171-193. https://doi.org/10.1080/02699939308409183

Rimé, B. (1989). Le partage social des émotions. [The social sharing of emotions]. In B. Rimé \& K. Scherer (Eds.), Les émotions (pp. 271-303). Neuchâtel : Delachaux et Niestlé.

Rimé, B. (2005). Le partage social des émotions [The social sharing of emotions]. Paris: PUF.

Rimé, B. (2009). Emotion elicits the social sharing of emotion: Theory and empirical review. Emotion Review, 1, $60-85$. https://doi.org/10.1177/1754073908097189

Rimé, B., Bouchat, P., Paquot, L., \& Giglio, L. (In Press). Intrapersonal, interpersonal and social outcomes of the social sharing of emotion. Current Opinions in Psychology.

Rimé, B., Finkenauer, C., Luminet, O., Zech, E., \& Philippot, P. (1998). Social sharing of emotion: New evidence and new questions. In W. Stroebe \& M. Hewstone (Eds.), European review of social psychology (Vol. 9, pp. 145189). Chichester, UK: John Wiley \& Sons Ltd. https://doi.org/10.1080/14792779843000072 
Rimé, B., Mesquita, B., Philippot, P., \& Boca, S. (1991). Beyond the emotional event: Six studies on the social sharing of emotion. Cognition and Emotion, 5, 435-465. https://doi.org/10.1080/02699939108411052

Rose, A. J. (2002). Co-rumination in the friendships of girls and boys, Child Development, 73, 1830-1843. https://doi.org/10.1111/1467-8624.00509

Savickas, M. \& Pouyaud, J. (2016). Concevoir et construire sa vie: un modèle général pour l'accompagnement en orientation au XXIème siècle [Life design: A general model for career intervention in the 21 st century]. Psychologie Française, 61, 5-14. https://doi.org/10.1016/j.psfr.2013.11.003

Schachter, S. (1959). The psychology of affiliation: Experimental studies of the sources of gregariousness (No. 1). Stanford University Press.

Schlossberg, N. K. (2005). Counseling adults in transition: Linking practice with theory. Springer Publishing Company.

Scott, S., Briskman, J., Woolgar, M., Humayun, S., \& O’Connor, T.G. (2011). Attachment in adolescence: Overlap with parenting and unique prediction of behavioural adjustment. Journal of Child Psychology and Psychiatry, 52, 1052-1062. https://doi.org/10.1111/j.1469-7610.2011.02453.x

Sharf, R. S. (2013). Advances in theories of career development. In W. B. Walsh, M. L. Savickas, and P. J. Hartung (Eds). Handbook of vocational psychology (fourth edition, pp 3-32). New York: Routledge.

Schultheiss-Palladino, D.E., \& Blustein, D. L. (1994). Role of adolescent-parent relationships in college student development and adjustment, of Counseling Psychology, 41, 248-255. http://dx.doi.org/10.1037/00220167.41 .2 .248

Thoits, P.A. (1984). Coping, social support, and psychological outcomes, in P. Shavers (Ed.)., Review of Personality and Social Psychology (vol. 5, p. 219-238). Beverly Hills, CA: Sage.

Thompson, S.C., and Janigian, A.S. (1988). Life schemes: a framework for understanding the search for meaning. Journal of Social and Clinical Psychology, 7, 260-280. https://doi.org/10.1521/jscp.1988.7.2-3.260

Vallerand, R. J. (1989). Vers une méthodologie de validation transculturelle de questionnaires psychologiques: implications pour la recherche en langue française [Towards a transcultural validation methodology for psychological questionnaires: implications for French language research]. Psychologie Canadienne, 30, 662689.http://dx.doi.org/10.1037/h0079856

Vasalampi, K., Salmela-Aro, K., \& Nurmi, J. E. (2010). Education-related goal appraisals and self-esteem during the transition to secondary education: A longitudinal study. International Journal of Behavioral Development, 34(6), 481-490. https://doi.org/10.1177/0165025409359888 
Vignoli, E. (2011). Les décisions d'orientation scolaire à l'adolescence : avec qui partager ses expériences émotionnelles, comment et pourquoi ? [College vocational decisions during adolescence: how, why and with whom sharing emotional experiences?]. Enfance, 4, 465-496.

Vignoli, E., \& Mallet, P. (2012). Les peurs des adolescents concernant leur avenir scolaire et professionnel : Structure et variations selon le niveau scolaire, le sexe et la classe sociale. [Adolescents' fears about their school and career future: structure and variations across academic level, sex, and social class.] Cahiers Internationaux de Psychologie Sociale, 94, 249-283.

Vignoli, E., Nils, F., \& Rimé, B. (2005). Partage social d'un épisode émotionnel d'orientation scolaire : L'avis du conseil de classe chez les adolescents de troisième [Social sharing of a vocational emotional episode : The class council opinion among third grade adolescents]. L'orientation scolaire et professionnelle, 34, 323-336.

Vignoli, E. (2009). Inter-relationships among attachment to mother and father, self-esteem, and career indecision. Journal of Vocational Behavior, 75, 91-99. https://doi.org/10.1016/j.jvb.2009.04.007

Young, R. A., Marshall, S. K., Domene, J. F., Graham, M., Logan, C., Zaidman-Zait, A., \& Lee, C. M. (2008). Transition to adulthood as a parent-youth project: Governance transfer, career promotion, and relational processes. Journal of Counseling Psychology, 55, 297-307. http://dx.doi.org/10.1037/0022-0167.55.3.297

Youngstrom, E. A., \& Green, K. W. (2003). Reliability generalization of self-report of emotions when using the Differential Emotions Scale. Educational and Psychological Measurement, 63, 279-295. https://doi.org/10.1177/0013164403253226

Zech, E., \& Rimé, B. (2005). Is talking about an emotional experience helpful? Effects on emotional recovery and perceived benefits. Clinical Psychology \& Psychotherapy: An International Journal of Theory \& Practice, 12, 270-287. https://doi.org/10.1002/cpp.460 
Table 1. Targets of vocational sharing according to the class council decision.

\begin{tabular}{|c|c|c|c|c|c|}
\hline \multirow[b]{2}{*}{ Vocational sharing with } & \multicolumn{2}{|c|}{ Favorable opinion } & \multicolumn{2}{|c|}{ Unfavorable opinion } & \multirow[b]{2}{*}{$\chi^{2}(\mathrm{df})$} \\
\hline & Yes & No & Yes & No & \\
\hline Mother & $89.7 \%$ & $10.3 \%$ & $81.1 \%$ & $18.9 \%$ & $5.36(1)^{*}$ \\
\hline Father & $72.7 \%$ & $27.3 \%$ & $54.5 \%$ & $45.5 \%$ & $12.51(1)^{* * *}$ \\
\hline Brother & $25.1 \%$ & $74.9 \%$ & $25.7 \%$ & $74.3 \%$ & $0.01(1)$ \\
\hline Sister & $34.1 \%$ & $65.9 \%$ & $34.6 \%$ & $65.4 \%$ & $0.01(1)$ \\
\hline Best friend & $77.2 \%$ & $22.8 \%$ & $70.1 \%$ & $29.9 \%$ & $2.23(1)$ \\
\hline Classmate & $72 \%$ & $28 \%$ & $80.5 \%$ & $19.5 \%$ & $3.43(1)$ \\
\hline Teacher & $26.7 \%$ & $73.3 \%$ & $47.8 \%$ & $52.2 \%$ & $16.56(1)^{* * *}$ \\
\hline Counselor & $12.4 \%$ & $87.6 \%$ & $23 \%$ & $77 \%$ & $6.59(1)^{*}$ \\
\hline
\end{tabular}

Note. $\mathrm{N}=357 * p<.05 . * * p<.01 . * * * p<.001$. 
Table 2. Reasons for social sharing according to the valence of the school council advice

\begin{tabular}{|c|c|c|c|c|c|}
\hline \multirow[b]{3}{*}{ Motive for sharing } & \multicolumn{4}{|c|}{ Valence of the class council advice } & \multirow[b]{3}{*}{$t$} \\
\hline & \multicolumn{2}{|c|}{ Favorable } & \multicolumn{2}{|c|}{ Unfavorable } & \\
\hline & $\mathrm{M}$ & SD & $\mathrm{M}$ & SD & \\
\hline Clarification, meaning making & 1.89 & 0.90 & 2.13 & 0.93 & $-1.92 *$ \\
\hline Relive, remember the emotion & 1.67 & 0.83 & 1.68 & 0.76 & 0.13 \\
\hline Reduce the emotional load & 1.86 & 1.05 & 2.45 & 1.20 & $-3.77 * * *$ \\
\hline Induce attention and empathy & 1.81 & 0.70 & 1.94 & 0.85 & -1.13 \\
\hline Inform and warn others & 3.36 & 1.09 & 3.07 & 1.13 & $1.92 *$ \\
\hline Seeking for support, comfort & 1.77 & 0.89 & 2.19 & 1.03 & $-3.14 * *$ \\
\hline Seeking for advice, guidance & 2.48 & 0.84 & 2.51 & 0.81 & -0.27 \\
\hline Self-worth & 1,99 & 0,94 & 1,75 & 0,91 & 1.86 \\
\hline
\end{tabular}

Note. ${ }^{*} p<.05, * * \mathrm{p}<.01, * * * p<.001$ 
Table 3. Multigroup path models comparisons.

$$
\operatorname{MLR} \chi^{2}(\mathrm{df})
$$

$\mathrm{SC}$

$\Delta \operatorname{MLR} \chi^{2}(\mathrm{df})$

RMSEA [ $90 \% \mathrm{CI}]$

CFI

SRMR

Sharing with mother

Baseline model

$40.73(16)^{* * *} \quad 1.0386$

$9.15(12)$

$.10[.06 ; .14]$

$.93 \quad .06$

Constrained model

$49.16(28)^{* *} \quad 1.0656$

$.07[.04 ; .10]$

.94

.07

Sharing with father

Baseline model
Constrained model

$49.40(16)^{* * *} \quad 0.9698$

-
$17.78(12)$

$.12[.08 ; .16]$

.90

.06

with best friend

Sharing with best friend

$66.34(28) * * * \quad 1.0026$

.10 [.07; .13]

.88

.07

Baseline model

$34.83(16)^{* *} \quad 1.0104$

1.0022

$9.41(12)$

$.09[.05 ; .13]$

$.93 \quad .06$

Constrained model

$44.42(28)^{*}$

Note. $\mathrm{MLR} \chi^{2}=$ chi-square test of model fit associated with robust maximum likelihood estimator; $\mathrm{df}=$ degrees of freedom; $\mathrm{SC}=$

$.06[.02 ; .10]$

$.94 \quad .07$ scaling correction factor; RMSEA = root mean square error of approximation; CFI = comparative fit index; SRMR $=$ standardized root mean residual. 
Figure 1. Multigroup path model of vocational sharing with the mother

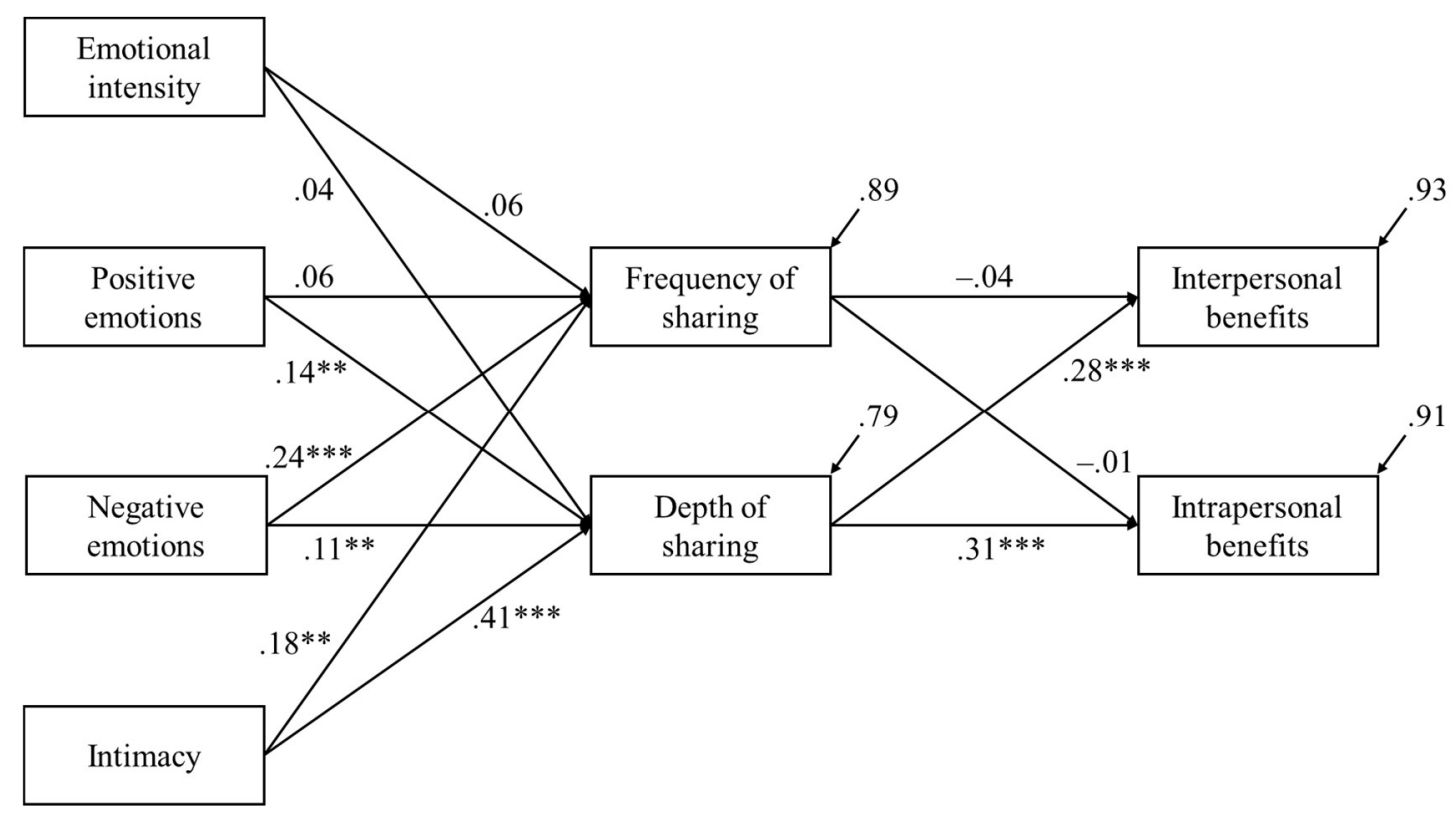

Note. Standardized parameters are displayed. Covariances between independent variables and between disturbances of dependent variables are not displayed for readability. $* p<.05 . * * p<.01 . * * * p<.001$.

Figure 2. Multigroup path model of vocational sharing with the father

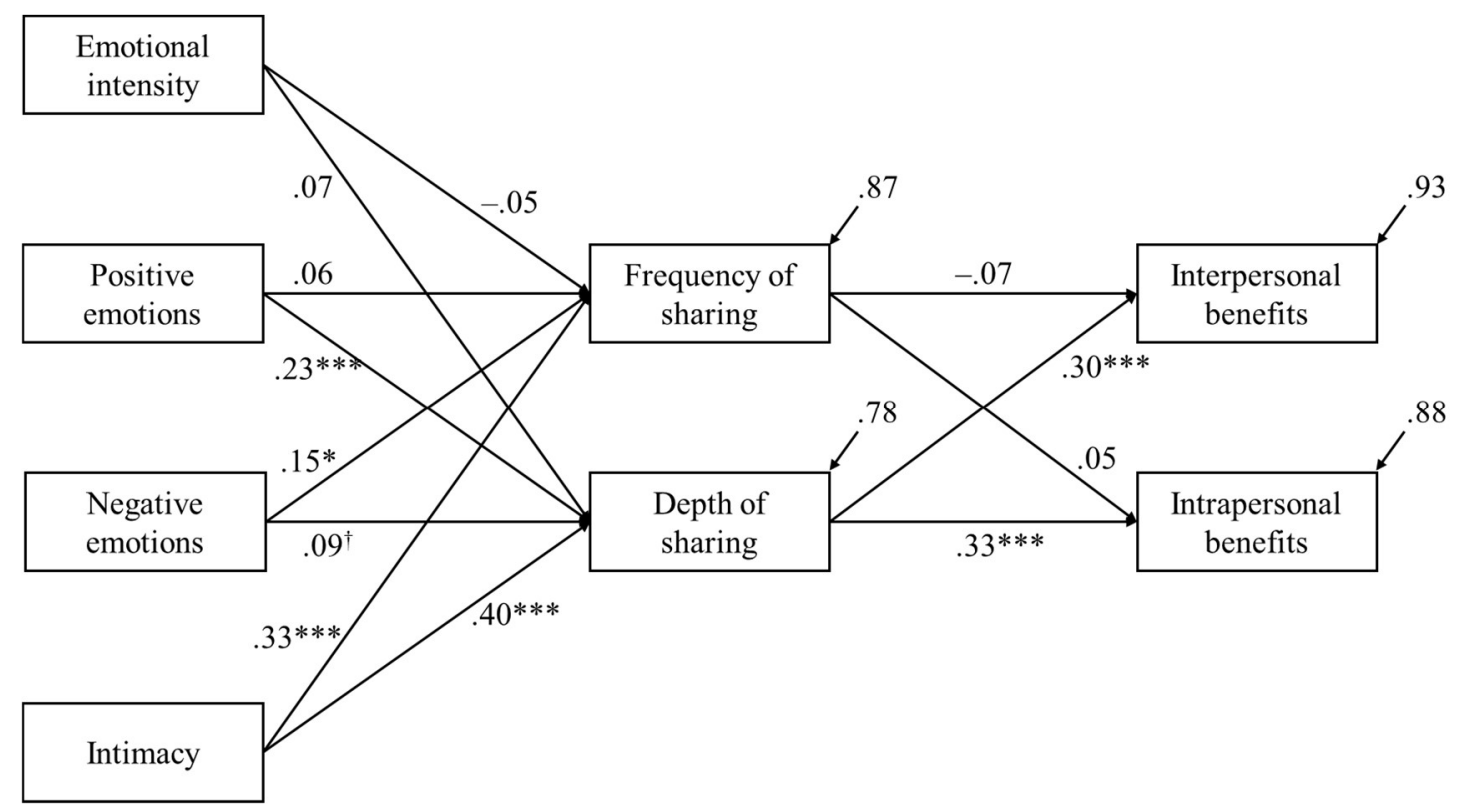

Note. Standardized parameters are displayed. Covariances between independent variables and between disturbances of dependent variables are not displayed for readability. ${ }^{*} p<.05$. $* * p<.01 .{ }^{* * *} p<.001$. 
Figure 3. Multigroup path model of vocational sharing with the best friend

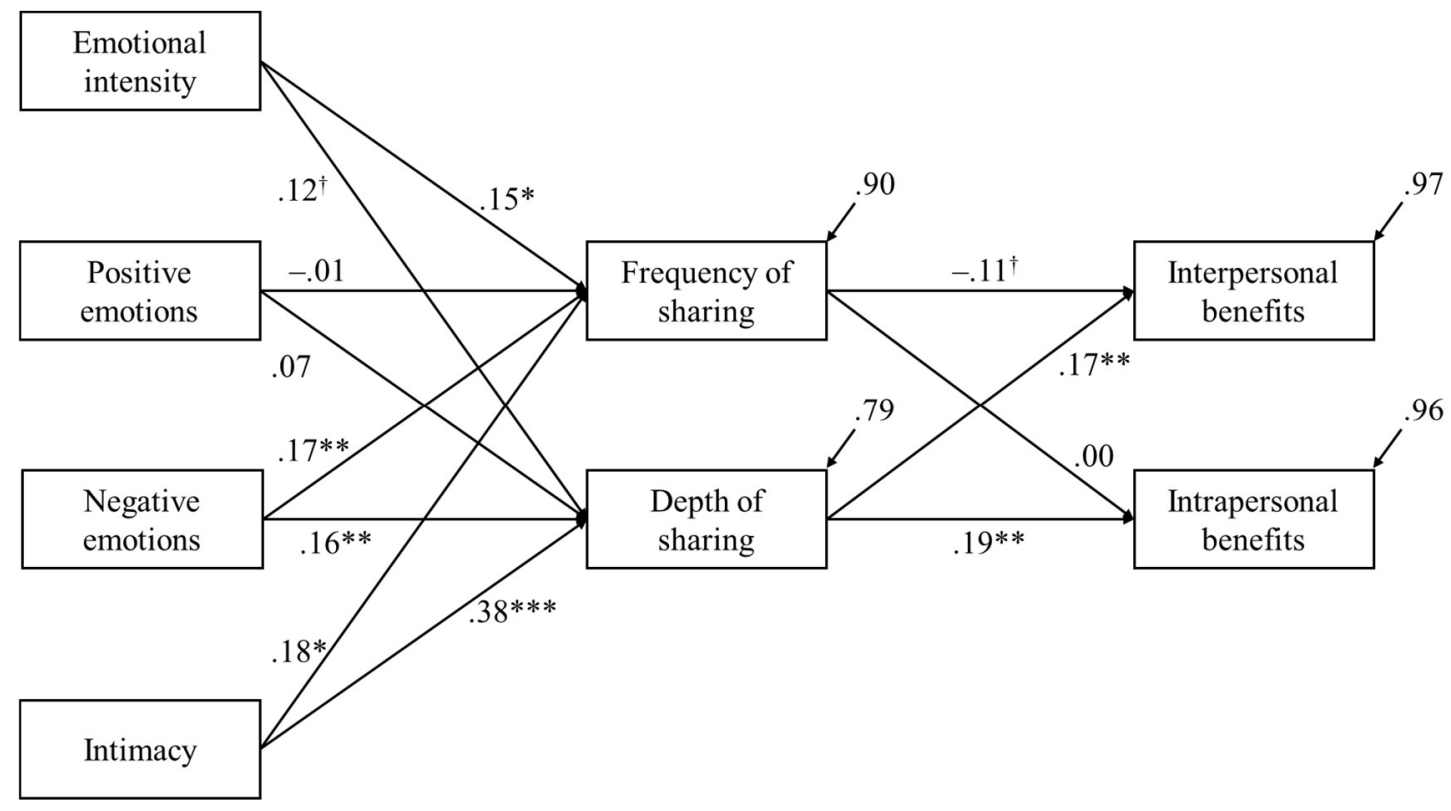

Note. Standardized parameters are displayed. Covariances between independent variables and between disturbances of dependent variables are not displayed for readability. ${ }^{*} p<.05 . * * p<.01 . * * * p<.001$. 